\title{
Sentient: A social media environment as a conscious living system
}

\author{
Lila Moore \\ Alef Trust \\ Somersby, Dibbinsdale Road \\ Wirral, United Kingdom \\ lila.moore@aleftrust.org
}

\author{
Owen Fender \\ Alef Trust \\ Somersby, Dibbinsdale Road \\ Wirral, United Kingdom \\ owenfender@yahoo.co.uk
}

\begin{abstract}
During the COVID-19 pandemic, the internet has become a global survival strategy. As a result, the need for an online platform, where participants can connect with each other on a deeper level than is possible on existing social media, has acquired a fresh urgency. We have decided to call this platform Sentient. The interface design draws on Rupert Sheldrake's system of biological and social morphogenic fields, as well as Arthur Koestler's theory of holarchy, among others. It will have the structure of a living body, possessing the seven processes vital to life, and holarchical systems ranging in scale from the subcellular to the whole organism. Users can create memes which evolve through conscious verbal and non-verbal interactions with other participants' memes. Sentient's live events are perceived as the ritualistic heart-beat that regularly generates the subtle body of the environment. Drawing on Roy Ascott's theory of technoetics, as well as cyberperformance aesthetics, the live events, including all modes of activity and interchange, are being designed to have a transformative as well as therapeutic function through participation. Sentient is developed on the premise that telematic technology can be converted into a conscious living system, leading to a holistic worldview of human and planetary life.
\end{abstract}

Social media. Cyberperformance. Technoetics. Telematics. Morphic resonance. Embodiment. Transpersonal.

\section{INTRODUCTION}

In the article 'Is There Love in the Telematic Embrace?' Roy Ascott describes telematic communication networks as a grid overlapping the earth in the form of a 'subtle body' (Ascott 1990, p.242). Ascott refers to David Tansley, who writes that the physical body has a double, named the etheric body, which is its subtle dimension that contains and determines all its biological components and functions. He describes the subtle body as a 'web of energy streams' (Tansley 1984, p.23). The subtle body transmits prana, the universal life force, in and out of the physical body. Telematic infrastructure could function like a subtle body. Beyond technological exchange of information, telematics can generate an interchange that leads to the harmonisation, and creative development of humanity and the planetary environment (Ascott 1990).
During the COVID-19 pandemic, the internet has become a global 'survival strategy' (Jamieson 2021). As a result, the need for an online platform, where participants can connect with each other on a deeper level than is possible on existing social media, has acquired a fresh urgency. We have decided to call this platform Sentient. The interface design draws on Rupert Sheldrake's system of units of biological and social morphogenic fields, and takes the form of a holarchy (first proposed by Arthur Koestler) (Sheldrake 2011; Koestler 1968). It will have the structure of a living body, possessing the seven processes vital to life, and holarchical systems ranging in scale from the subcellular to the whole organism. The live streaming and networked performative events are perceived as the ritualistic heart-beat that regularly transmits the subtle body of the environment. They are being designed to have a transformative as well as therapeutic function through participation. 


\section{PROJECT OUTLINE}

Sentient's pilot period as a research project is from September 2020 to December 2021. Our main research question is: How can subjective, transpersonal experience be given greater prominence in a live streaming and social media context, to enable positive, long-lasting transformation of the participants involved? The research question is addressed through seven live events with real-time in-person and online participation, using Upstage and OBS. These will be streamed to our website and app, and simultaneously to platforms such as YouTube, Twitch, Periscope and Facebook Live. We will also create an expressive social media environment, beyond the limitations of existing social media, which can be accessed via an app designed for smartphones and tablets, and via our website, for desktop and laptop computers. It will involve the gradual creation of a 'living' archive of interactive art experiences, which can be drawn upon, transformed, reimagined etc.

We are working with a core group, who will participate in all the events, and who will maintain a constant presence in the social media environment. They provide creative feedback, and assist in the project development. The core group includes artists, designers, therapeutic and medical practitioners, teachers, scholars, and coding and IT professionals, who are engaged with spiritual and holistic practices. All have a pre-existing interest in the areas in which we're working, and share our aims for the project. We will also engage with a group of approximately 50 students in tertiary education, who will feed back their experience and suggestions. They will be drawn from the Alef Trust, Bath Spa University, and other institutions, and will be from any background, studying any subject, at any level. This group may or may not have any preexisting interest in transpersonal psychology, art or spirituality, but they will have an interest in aiding our research, and the enthusiasm to participate fully in the creation of a new, kinder social media.

We need to show how our proposed methodology can create a better online experience for everyone, not just those who already have an active interest in these areas. We will monitor participants' mood, wellbeing and progress throughout the live events via questionnaires and polling that can be written ahead of time, with everyone's creative input, and can be added simply to the live stream. We have carefully designed questionnaires that ask openended questions exploring participants' experience of existing social media before the start of the project, how it transforms during the pilot period, and how it compares to Sentient. This will provide us with a wealth of qualitative data to analyse. Moreover, the nature of the social media environment will itself allow participants to share how they feel directly, in real-time, and in more expressive ways than presently available. The events are being planned with members of our core group, utilising their skills in holistic therapies and mental health, education, the arts, and telematics. In time, we hope to host professionals offering services to their clients, utilising the increased options for interactivity that Sentient offers.

\section{A CONSCIOUS SOCIAL MEDIA ENVIRONMENT}

Sentient's users will be empowered to respond to collective experiences with feelings, sensations, intuitions, and perceptions, which will have an immediate impact on the nature of the experience, enabling a transformation of consciousness. By using abstract, poetic and archetypal forms of expression such as colour, sound, text, image, and movement, users will be free to connect with each other holistically from the core of their being to create something new. Their authentic voice will be heard in an honest environment, free from advertising and manipulative practices, that becomes more than the sum of its parts, and takes on the form of a living, growing, sentient organism.

The pilot stage is primarily for students 18 years old and above, practitioners of holistic therapies, and those who wish to take part in an exciting experiment in the creation of a deeper, more holistic social media, where less attention is paid to surface appearances, and more to what lies underneath. Students and young people in general, who have never known a world without the internet, are particularly susceptible to the manipulative, behaviour-modifying algorithms that existing social media platforms use as the basis for their business model. These companies exploit a vulnerability in human psychology by stimulating a low-level threat response in users, and trapping them in a socialvalidation feedback loop that administers a small dopamine hit every time something they shared is liked or commented upon (Lanier 2018, p. 8).

This is a vicious circle, which becomes more vicious once a bad actor realises they can get far more attention from negative behaviour than from positive. Other users, who are well-meaning, experience a zombie-like effect (ibid. p. 42), where they are frightened to be themselves in the artificial space, and so conform to what they believe is normal. Hence, avatars which can be utilised for selfknowledge, explorations and elaborations on identity are reduced to merely surface appearances. Sentient would 'hack' this vicious circle, and transform it into a virtuous circle - a positive feedback loop - by providing users with a nurturing, safe, and most importantly, non-manipulative 
alternative, where people would be free to express themselves without fear of negative repercussions, such as troll behaviour (March 2019; Sest \& March 2019).

By taking back their power, participants will be able to interact with each other on their own terms, and together will be able to invent a new pattern of civilization, a process termed in networked media theory as 'the build' and world-building (Youngblood 2013), free from manipulative practices serving opaque, shadowy purposes. The negative psychological effects, which at the lowest level, cause irritability and paranoia (the diffuse forms of fight or flight), can at the highest level radicalise people, turning them towards extremism (Herzog 2016; Lanier 2018, p. 149; Orlowski 2020). People will be empowered to shape the environment they want, on equal terms in an honest authentic space. They will be inspired to forge new paths, and serve as inspiration to others.

Recent global events have shown that people, especially the young, care a lot about issues relating to identity, democracy, ecology and the environment, gender issues, and much more. They naturally exist in social media environments. Their computers have become their scientific labs, temples and sacred places, sports and dance studios, personal diaries, as well as artists' studios, as evidenced, for example, in The New Art Fest 2020. Young people live in a global media village, and are more receptive to ideas that are both local and global, physical and virtual. They care about social media because they care about their virtual homes and wish to constantly improve their online and offline experiences. Young people are curious about their media environments, and constantly seek to advance them. Sentient will present an opportunity to share and discover the profoundly personal and spiritual dimensions of life, forming a safe bounded space where potential and vision are encouraged to grow in a more empathic way.

\section{CYBERPERFORMANCE AND LIVE NETWORKED EVENTS}

Our approach to live events is informed by the aesthetics and theories of cyberperformance (Abrahams \& Jamieson 2014) and networked art and performance (Moore 2015). Hence, we are using UpStage (the newly updated platform) for our current experiments, as well as integrating live performance in the social media space. We are also experimenting with strategies that embed the experience of the live event in a mixed reality environment. For example, by collaborating with a permaculture project in Merseyside, data from $\mathrm{CO} 2$ and light sensors can be shared with a wider audience; processes involved in photosynthesis such as the amount of carbon dioxide transformed into oxygen, or the amount of sunlight falling on the plants, can be live-streamed, and converted into images and music, with which people can interact in a meaningful way. Participants from around the world will be able to interact with this event via their smartphones, while sitting or walking in a natural environment or a garden, or even in an urban park. In a mixed-reality environment, the smartphone thus becomes a technological instrument that serves the connectivity with the natural environment rather than becoming the focus of attention, which in turn becomes the actual holistic experience of photosynthesis.

Another example of a planned live event is an encounter with Perneb - as discussed in a previous EVA presentation and paper - which cannot be completed without re-connecting his burial chamber in Saqqara Egypt and his tomb at The Met, through a livestreaming performative and participatory event (Moore 2019). In this case, connectivity serves not only a geographically remote operation, but also a mythical and ceremonial performance with cultural and educational merits. We will attempt to answer the question posed by Jaron Lanier in his book Ten Arguments For Deleting Your Social Media Accounts Right Now, 'How do we re-establish the primal rites that kept people safe, with a sense of belonging, in online space?' (Lanier 2018, p.16).

Moreover, live events will serve Sentient's community of holistic therapists and their clients for online/offline therapeutic activities. Live streams will run on the Sentient system around the clock, in tune with planetary locations and rhythms, inducing through the passage of time the environment's subtle body. These live streams will be operated by those who will choose to become regular inhabitants of the social media environment.

\section{INTERFACE DESIGN}

The Sentient environment will take the form of an abstracted human body. Each participant represents a cell in this body; aspects of their profile, such as personal details, media and memes, are the subcellular 'organelles', and their profile picture is the 'nucleus'. People accessing from a computer or tablet will experience an audiovisual representation of all the cells on the splash screen. However, most people in the UK now access the internet on smartphones (Ofcom 2020), so it is important to focus the design of Sentient to work on these devices. Though smartphones have limited screen space to work with, they offer many benefits, including sensors such as accelerometers (measuring movement), gyroscopes (measuring rotation), cameras, voice recording, and of course, touchscreens. These, combined with the fact that smartphones are with us at all times, make them highly conducive to a more expressive, gestural and human social media. 


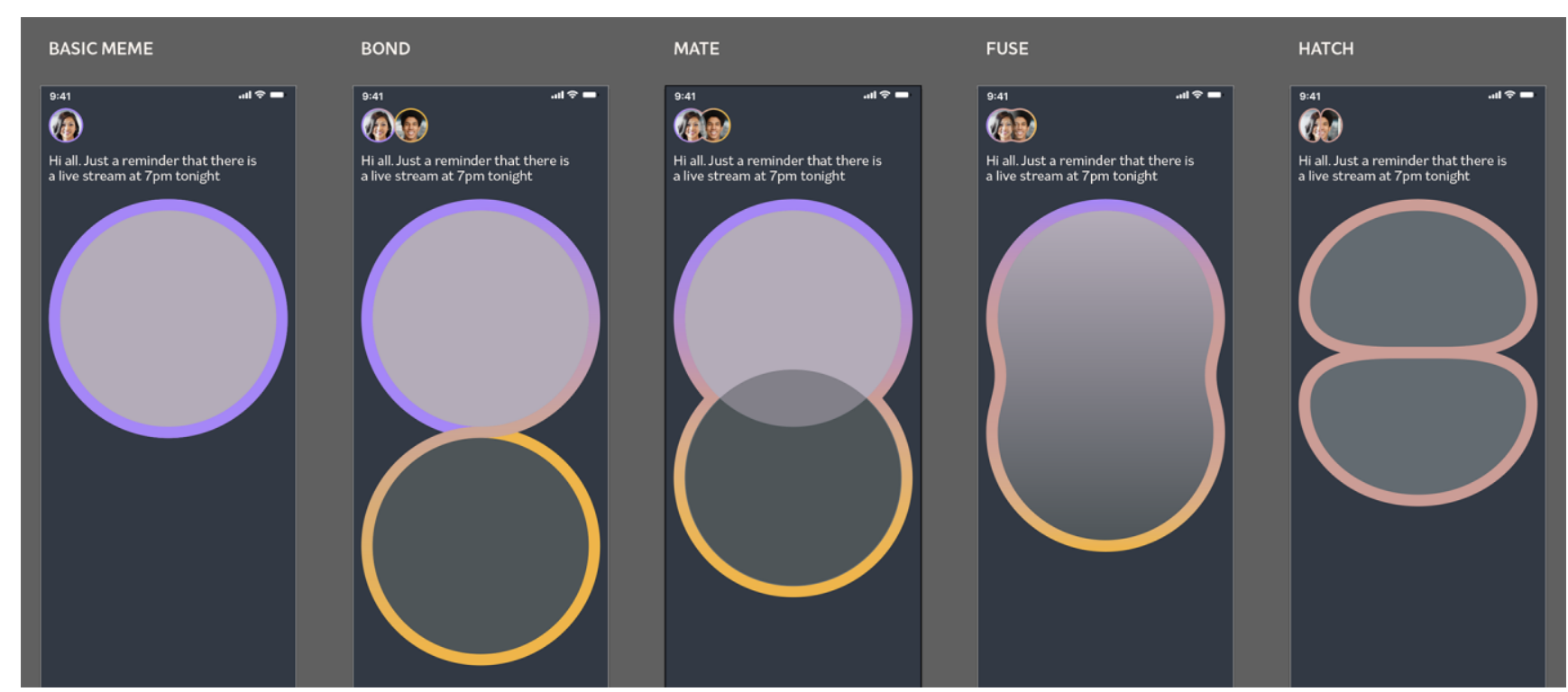

Figure 1: Meme growth stages - A participant can post a meme, with which other users have numerous ways to interact, including the opportunity to bond one of their own memes or other media to the original meme. Beyond that, further interactions cause increased integration of the memes until they are fully merged, and can 'give birth' to a new original meme.

In his hypothesis of the meme as a unit of cultural information spread by imitation, scientist Richard Dawkins states that, 'memes should be regarded as living structures, not just metaphorically but technically.' (Dawkins in Sheldrake 2011, Location: 5657) The scientist Rupert Sheldrake argues that:

cultural morphic fields are not atomic units of culture; like all other types of morphic fields, they are structured in nested hierarchies of fields. And they are not passed on solely by imitation, but their acquisition is favoured by morphic resonance.

(Sheldrake 2011, Location: 5664)

Thus, Sentient treats the meme as a living part of a greater organism. It can undergo transformation and evolution due to interactions with other parts of the living system, in a process that will naturally tend towards a stable pattern of organisation. Sheldrake adds:

According to the hypothesis of formative causation, the organization of social systems depends on nested hierarchies of morphic fields, with the overall field of the society organizing the individual animals within it through their morphic fields, which in turn organize their component organs, and so on down to the cellular and subcellular levels. (Sheldrake 2011, Location: 5288)

The transformation of memes takes on the form of cell growth and division. Thus, a simple meme can evolve into a rich, meaningful, co-created symbol, in which many people hold a stake (see Figure 1). This allows for the natural synthesis, development and maturation of ideas that are shared between participants, and can in turn give birth to wholly new creations.

There is an emphasis on subjective forms of communication, such as the sharing of sensations, feelings and perceptions, which can be expressed through colour, sound, touch and movement, as well as through writing, speech and figurative images. The tactile qualities of the touchscreen allow for physical interaction; at the most basic level, someone can simply touch a meme, leaving a trace to show that they have experienced it. They can also share a simple sound or vibration, utilising the vibration facility on most smartphones, or, utilising the accelerometer, a movement, which can be visualised or sonified, and replayed by other users. Bodily sensations and embodied emotions can be expressed by drawing on a representation of themselves, in the form of a human figure (see Figure 2), and feelings can be shared by generating abstract forms. The combined responses of participants create a living mandala of human experience, which surrounds the meme, and acts as a historical record, much like the growth rings of a tree (Figure 3 ).

These alternative modes of expression, or ways of knowing, help to break through the language, culture and other differences that often divide us. They also make it easier for those who, for whatever reason, find it difficult to express themselves in words. Beyond that, they aid us all in communicating that which is difficult, or indeed impossible to express - 

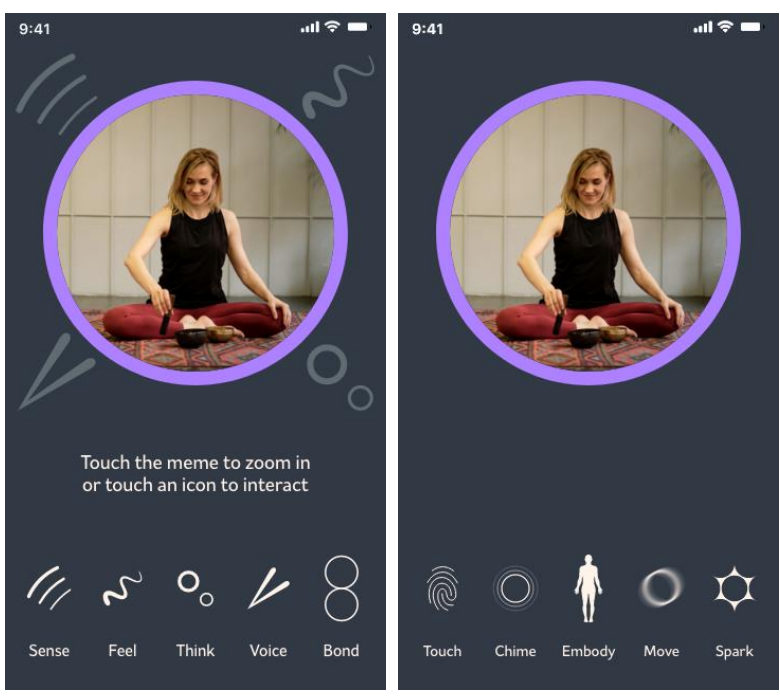

Figure 2: In this example, someone can share bodily sensations by painting on the figure of a human.
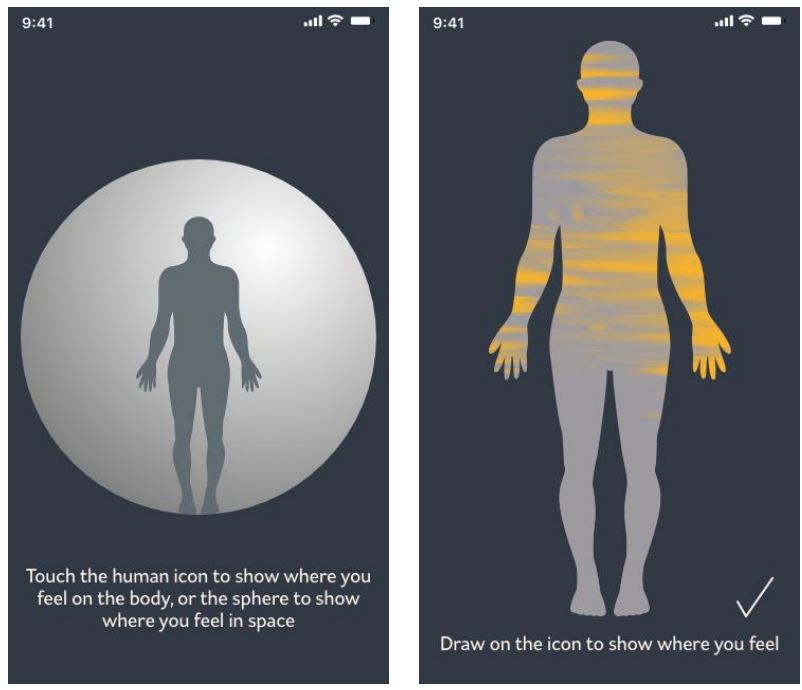

the sense of wonder, humility and compassion which is beyond words, and which, if shared, can add meaning and richness to our collective experience.

Psychologist Clare Graves's theory of Spiral Dynamics proposes that consciousness is:

an unfolding, emergent, oscillating spiraling process marked by progressive subordination of older, lower-order behavior systems to newer, higher-order systems...proceeding through eight general stages, which are also called memes...for Spiral Dynamics a meme is simply a basic stage of development that can be expressed in any activity (Graves 1981, in Wilber 2001, pp. 6-7)

The memes shared in Sentient undergo similar development, which are also analogous to the seven life processes of movement, respiration, sensitivity, growth, reproduction, excretion and
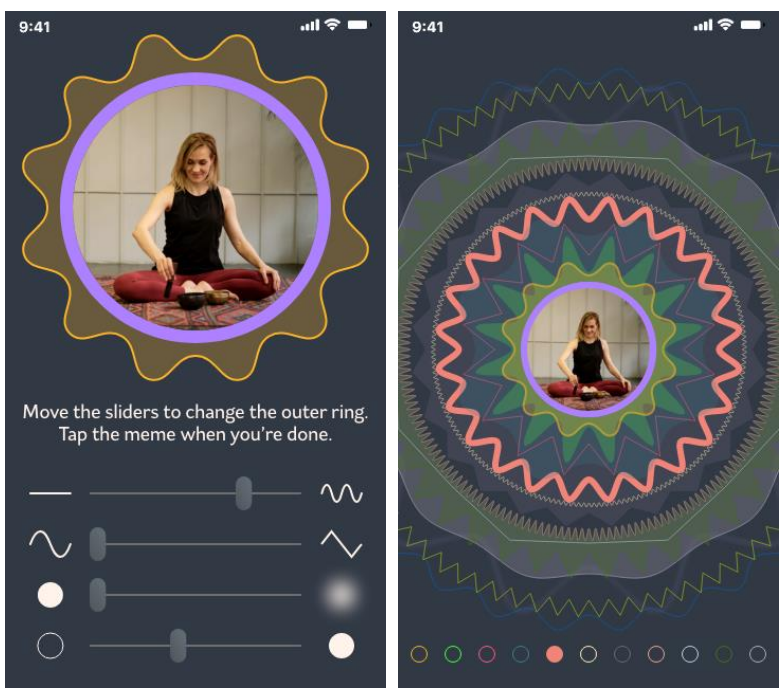

Figure 3: Feelings can be expressed in an abstract form by making alterations to a simple circle. The combined feeling responses can be viewed as a mandala surrounding the original meme.

nutrition. The design of the space allows participants to form groups which take the form of tissues or organs in the greater organism. For example, moderation of posts can be carried out by the 'liver' and 'kidneys', removing toxins that may harm the system as a whole.

This approach marries well with Graves's eighth stage of human development, a 'Universal holistic system, [which] unites feeling with knowledge; multiple levels interwoven into one conscious system.' (Wilber 2001, p. 13) In Sentient, participants can still share written comments, links and photographs, but they are able to do so much more, and they are able to create deeper, more meaningful connections that grow organically. In this way the relations become as, or more important than the relata, and a participant is able to appreciate the gestalt, or overview of the entire space, as well as their place in it (see Figure 4).

We expect to make a positive impact on the wellbeing of all participants. We will suggest a creative new form of social media, where surface appearances are less important, and the difference between professional/layman and between self/other is blurred or even eradicated. We would expect participants to gain a new set of tools for being in the world (both virtual and real), and to act as trailblazers for a new way of being, influencing their peers, and helping to grow the environment. Participants will feel not only that they are heard and seen, but that they are part of something bigger, and as a result, they will be empowered to engage with their daily lives with an enhanced sense of meaning. By concentrating on inner experience, subjective reality, selfexpression, and transpersonal states of 


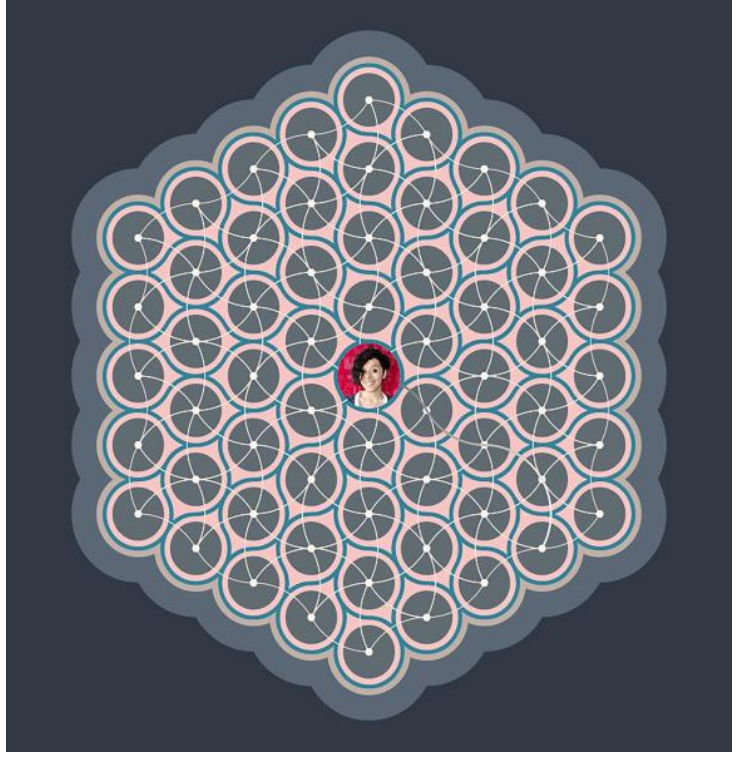

Figure 4: The combination of body systems is viewable on a map, where a participant can see how they fit in the greater organism.

consciousness, we are confident that there will be a positive transformation of everyone involved.

Beyond the pilot stage, we have faith that Sentient can become a viable alternative to existing social media, and grow globally. As technological change accelerates, with widespread adoption of mixed reality, and the internet of things, Sentient will assist people to navigate safely the complex layers of a multi-dimensional reality which, without examination, care and attention, threaten to overwhelm and alienate us. It will also provide a safe space for the exploration of what it means to be human in an increasingly posthuman existence. Technology itself isn't the problem, but it needs to be integrated holistically into our lives and environments, to aid humanity's wellbeing.

\section{CONCLUSION}

According to Karousos (2016, p. 292), unless we bring the love that technoetics brings to telematics, "cyberspace remains another same space that intelligent man should conquer in order to preserve his title as the fittest of the fitting.' Sentient provides a framework for creative research of notions such as: 'networked mind' (Moore 2015) 'field of consciousness' (Ascott 2013, p.52), and Pierre Teilhard de Chardin's 'noosphere' (Teilhard de Chardin 1967), as well as the brain/mind, as explored together by new media artists, scientists and technologists (Trickett 2021). It will encourage exploration of transpersonal therapies, spiritual psychology, issues relating to identity, empathy, transformation, and more. These fields of research and practice will be explored in the context of social media and telematics.

\section{ACKNOWLEDGEMENTS:}

Sentient is a Conscious Community Project supported by Alef Trust. The core group includes Dr Kelly Morris (Medical Doctor), Sue Evans, (Spiritual Health Mentor), Kanchan Kulkarni, (Master NLP Coach and Hypnotist), Adi Vicker, (Co-director, Asana School of English), Vitaliy Dominichenko, (Transpersonal Coach, Software Developer, Musician).ret

\section{REFERENCES}

Abrahams, A. (2014) Learn Together What it Means to Be Connected ..., in Abrahams, A. \& Jamieson, V. H. (eds.). CyPosium - The Book, Brescia: Link Editions, Montpellier: La Panacée, Centre de Culture, France.

Ascott, R. \& Shanken, A. E.(eds.). (2003) Telematic Embrace: Visionary Theories of Art, Technology and Consciousness. Berkeley, CA: University of California Press.

Ascott, R. (1990) Is there love in the telematic embrace? Art Journal, 49, pp.241-47.

Dawkins, R. (1976) The Selfish Gene. Oxford: Oxford University Press.

Graves, C. (1974) Summary Statement: The Emergent, Cyclical, Double-Helix Model of the Adult Human Biopsychosocial Systems. Boston. https://www.clarewgraves.com/articles content/198 1 handout/1981 summary.pdf (retrieved 15 March 2021).

Jamieson, V. H. (n.d.) Cyberperformance. https://www.creative-catalyst.com/cyberformance (retrieved 15 March 2021).

Karoussos, E. (2016) Theōria: The veneration of icons via the technoetic process. Doctoral dissertation, University of Plymouth.

Koestler, A. (1968) The Ghost in the Machine. New York: Macmillan.

Lanier, J. (2018) Ten Arguments For Deleting Your Social Media Accounts Right Now. New York: Henry Holt and Company, Picador. Kindle.

Lo and Behold: Reveries of the Connected World (2016). [film] Directed by Werner Herzog. USA

March, E. (2019) Psychopathy, sadism, empathy, and the motivation to cause harm: New evidence confirms malevolent nature of the internet troll, Personality and Individual Differences, 141, pp. 133-137. 
Moore, L. (2019) Tombs and reels of consciousness: The aesthetics that Interlinks ancient ritualistic artefacts and digital, augmented and virtual reality. In: Weinel, J., Bowen, J.P., Diprose, G., and Lambert, N. (eds), EVA London 2019 (Electronic Visualisation and the Arts), UK, 11-13 July 2019, 155-161. BCS, London.

Moore, L. (2015) Fields of networked mind: ritual consciousness and the factor of communitas in networked rites of compassion, Technoetic Arts: $A$ Journal of Speculative Research,13, (3), pp. 331339.

Ofcom.

https://www.ofcom.org.uk/ data/assets/pdf file/00 27/196407/online-nation-2020-report.pdf (retrieved 14 March 2021).

Sest, N. \& March, E. (2017) Constructing the cybertroll: Psychopathy, sadism, and empathy. Personality and Individual Differences, 119, pp. 6972.
Sheldrake, R. (2011) The Presence of the Past: Morphic Resonance and the Habits of Nature. London: Icon Books. Kindle.

Tansley, V. D. (1984) The Subtle Body. New York: USA: Thames and Hudson.

Teilhard de Chardin, P. (1967) The Phenomenon of Man. London and Glasgow: Collins Sons \& Co.

The Social Dilemma (2020) [film] Directed by Jeff Orlowski. USA.

Trickett, T. (2021) New media art as a vehicle for research and innovation. In: Weinel, J., Bowen, J.P., Borda, A., and Diprose, G. (eds), EVA London 2021 (Electronic Visualisation and the Arts), London, UK, 5-9 July 2021 BCS, London.

Wilber, K. (2001) A Theory of Everything. Boston: Shambala Publications.

Youngblood, G. (2013) Secession from the Broadcast, https://wiki.p2pfoundation.net/Secession From the Broadcast (retrieved 16 March 2021). 